\title{
The Impact of the Coronavirus Disease - 19 Pandemic on the Treatment of Acute Appendicitis: Presentation, Outcomes, Strategies of Acute Appendicitis During Coronavirus Disease -19 Pandemic
}

\section{Sanghyun An}

Yonsei University Wonju College of Medicine

Hae-Rim Kim

University of Seoul

\section{Sungwoo Jang}

Yonsei University Wonju College of Medicine

Kwangmin Kim ( $\square$ lukelike@yonsei.ac.kr)

Yonsei University Wonju College of Medicine

\section{Research Article}

Keywords: COVID-19, Coronavirus, Pandemic, Appendicitis, Appendectomy

Posted Date: February 16th, 2022

DOI: https://doi.org/10.21203/rs.3.rs-1352041/v1

License: (c) (i) This work is licensed under a Creative Commons Attribution 4.0 International License. Read Full License 


\section{Abstract}

Background: This study aimed to investigate the characteristics, severity, and treatment of patients with acute appendicitis in Korea over a 2-year period during the coronavirus disease (COVID-19) pandemic compared to those before the pandemic. We also investigated whether there were any changes in clinical characteristics of acute appendicitis before and after vaccination against the coronavirus.

Methods: We retrospectively reviewed the medical records of patients who were diagnosed with acute appendicitis at our institution between March 1, 2019, and August 31, 2021. We divided the patients into three groups (pre-pandemic, before vaccination, and after vaccination) and analyzed the clinical outcomes.

Results: The time from symptom onset to hospital arrival and the time from symptom onset to operation increased during the COVID-19 pandemic period compared to the pre-pandemic period. The rate of complicated appendicitis during the pandemic was higher than that before the pandemic. In addition, the number of new daily cases showed a positive correlation with the time from symptom onset to hospital arrival $(\mathrm{OR}, 0.03 ; 95 \% \mathrm{Cl}, 0.02$ to $0.04 ; \mathrm{P}<0.001)$ and complicated appendicitis $(\mathrm{OR}, 1.002 ; 95 \% \mathrm{Cl}, 1.001-1.002 ; \mathrm{P}=0.0017)$. The vaccination rate showed a negative correlation with the time from symptom onset to hospital arrival $(\mathrm{OR},-2.26 ; 95 \% \mathrm{Cl},-3.42$ to $-1.11 ; \mathrm{P}<0.001)$ and complicated appendicitis $(\mathrm{OR}$, $0.915 ; 95 \% \mathrm{Cl}, 0.84$ to $0.996 ; \mathrm{P}=0.0404)$.

Conclusions: Employing hospital-wide efforts, such as screening by rapid PCR testing, to avoid further time delays, and nationwide efforts, such as vaccination, to shorten the time from symptom onset to hospital arrival, are necessary to maintain the quality of treatment of acute appendicitis during an infectious disease pandemic.

\section{Introduction}

Coronavirus disease (COVID-19) is an infectious disease caused by severe acute respiratory syndrome coronavirus 2 (SARS-CoV-2) and was first reported in Wuhan, Hubei, China in December 2019 [1]. The virus, which can spread through direct contact, aerosols, and airborne droplets, mainly affects the upper respiratory tract and can cause pneumonia in severe cases. This highly contagious virus spread all over the world in a short time, leading the World Health Organization to declare COVID-19 a pandemic on March 11, 2020 [2]. With the spread of COVID-19, many countries declared a state of emergency and instituted partial or full restrictions on social activities [3]. Furthermore, this global social atmosphere impacted the medical field as non-urgent medical services were recommended to be postponed [4]. Some studies have reported a significant reduction in the number of patient visits to hospitals, including emergency clinics, during the pandemic $[5,6]$. However, there are still inevitable and emergent clinical situations that require immediate treatment.

Acute appendicitis is one of the most common acute abdominal diseases requiring emergency treatment, and the lifetime risk of developing acute appendicitis is approximately $7-8 \%$ worldwide $[7,8]$. Emergency appendectomy is the treatment of choice, but there is still debate about its suitability in this pandemic era because several articles have reported that nonsurgical management, such as antibiotic therapy, is non-inferior to appendectomy $[9,10]$. In addition, it has been reported that initial non-surgical management, such as antibiotics, with or without percutaneous drainage followed by interval appendectomy in complicated cases such as periappendiceal abscess is effective and reduces postoperative complications compared to immediate appendectomy [11]. Moreover, a change in the main treatment strategy has been observed in some countries. In the UK, the antibiotic-first pathway has been accepted and implemented as the main treatment strategy for acute appendicitis in the era of the COVID-19 pandemic [12]. Other changes associated with the management of appendicitis during the COVID-19 pandemic were also reported in several studies; the number of patients visiting the hospital for acute appendicitis decreased and the time from symptom onset to hospital arrival (TSH) increased, resulting in an increase in complicated cases [13-15]. Further, the risk of complications such as perforation increased as 
the time from symptom onset to treatment became longer than $24 \mathrm{~h} \mathrm{[16].} \mathrm{However,} \mathrm{most} \mathrm{of} \mathrm{these} \mathrm{studies} \mathrm{are} \mathrm{reports} \mathrm{on} \mathrm{the}$ initial situation of the pandemic outbreak and do not reflect the post-vaccination changes or the current ongoing situation due to the mutant virus.

Therefore, this study aimed to investigate the changes in the characteristics, severity, and treatment of patients with acute appendicitis in Korea for 2 years following the advent of the COVID-19 pandemic compared to those during the prepandemic period. We also investigated the impact of the vaccinations against the coronavirus on the characteristics, severity, and treatment of patients with acute appendicitis. Furthermore, we investigated the factors associated with the outcomes.

\section{Methods}

\section{Study population}

We retrospectively reviewed the medical records of patients who were diagnosed with acute appendicitis at Yonsei University Wonju Severance Christian Hospital, Republic of Korea, from March 1, 2019, to August 31, 2021. During this period, 659 patients were diagnosed with acute appendicitis in the emergency clinic. Of these, we excluded patients who were younger than 18 years, pregnant, diagnosed with benign or malignant neoplasm on pathological examination, referred from other departments or hospitals (e.g., misdiagnosis) and underwent combined operation and those who did not undergo appendectomy at initial diagnosis. Finally, 484 participants were included in the study (Fig. 1). This study was approved by the Institutional Review Board of Yonsei University Wonju Severance Christian Hospital (IRB no. CR321177). Because this study was conducted retrospectively, informed consent was waived.

\section{COVID-19 pandemic and vaccination in the Republic of Korea}

The first case of COVID-19 in the Republic of Korea occurred on January 20, 2020, and the first outbreak started on February 18, 2020. Since then, the number of confirmed cases of COVID-19 has continued to increase; as of August 31, 2021, the cumulative number of confirmed cases was 253,445. In Korea, vaccination for COVID-19 began on February 26, 2021 , and the percentage of fully vaccinated individuals on August 31, 2021, was $31.1 \%$ (Fig. 2) [17]. In this study, the period before the first outbreak (February 18,2020) has been defined as pre-pandemic (PP) and that after the first outbreak as pandemic $(P)$. We further divided the pandemic group into the before-vaccination period $(P-B V)$ and after-vaccination period (P-AV) based on the starting date of vaccinations in Korea. We defined the completion of vaccination as up to the second vaccination.

\section{Data collection}

Demographic characteristics of the patients, including age, sex, pulse rate, body temperature at arrival, length of stay after operation (LOS), operation time, duration of antibiotic use, TSH, time from hospital arrival to operation (THO), time from symptom onset to operation (TSO), American Society of Anesthesiologists physical status (ASA) score, medical history, type of operation, whether laparotomy or laparoscopy was performed, whether open conversion during laparoscopy was performed, whether the drain was inserted after the operation, radiological findings (acute inflammation, periappendiceal abscess with localized peritonitis, generalized peritonitis), pathological findings (acute inflammation, suppurative, gangrenous, perforation, abscess), postoperative complications, and re-visit to the emergency department or re-admission within 30 days after operation, were obtained from medical records. Initial laboratory results including white blood cell counts (WBC), hemoglobin ( $\mathrm{Hb})$, platelet count (PLT), neutrophil count, lymphocyte count, delta neutrophil index (DNI), and C-reactive protein (CRP) levels were also obtained. The type of operation performed was categorized as follows: appendectomy, partial cecectomy, ileocecectomy, and right hemicolectomy. To analyze the correlation between 
the transmission rate of COVID-19 and the clinical features of appendicitis, the number of daily confirmed cases of COVID19 and the vaccination rates on the day of hospitalization were also investigated using data from the Korea Centers for Disease Control and Prevention.

\section{Definitions}

Appendicitis is divided into simple appendicitis and complicated appendicitis. In our study, complicated appendicitis was defined as one or more of the following three findings: 1. Cases that underwent additional bowel resection (e.g., partial cecectomy, ileocecectomy, or right hemicolectomy); 2. Presence of pathological findings such as gangrenous inflammation, perforation, or periappendiceal abscess; and 3. Presence of radiological findings such as localized peritonitis with abscess formation or generalized peritonitis.

\section{Statistical analysis}

The patients were classified into three groups based on their date of visit to the emergency clinic, namely, pre-pandemic $(\mathrm{PP})$, pandemic (P-BV), or pandemic (P-AV). Continuous variables are expressed as median (interquartile range $[\mathrm{IQR}]$ ), and categorical variables are expressed as frequencies and percentages. Continuous data were tested for normal distribution using the Shapiro-Wilk test and compared using the analysis of variance (ANOVA) test or the Kruskal-Wallis test, as appropriate. When a significant difference between the three groups was found in the ANOVA test or the KruskalWallis test, a post-hoc test was performed using the Benjamini-Yekutieli correction. Categorical variables were also tested for normality and compared using the chi-square test and Fisher's exact test, as appropriate. Binary logistic regression analysis was performed to identify factors associated with complicated appendicitis. Univariate and multivariate analyses were performed, and variables were selected automatically using backward stepwise selection. Linear regression analysis was also performed with TSH, THO, and TSO as dependent variables. Similarly, independent variables were selected for backward stepwise selection. Statistical significance was set at $p<0.05$, except Dunn's post-hoc test by Benjamini-Yekuteili adjustment. In the post-hoc test, the null hypothesis was rejected when $p<0.05 / 2$. Statistical analysis was performed using R statistical software (version 4.1.0; R Foundation for Statistical Computing, Vienna, Austria).

\section{Results}

\section{Comparison of patient characteristics between the three groups}

Among the 484 patients diagnosed with acute appendicitis who underwent emergency surgery, 201 and 283 patients were in the pre-pandemic and pandemic groups, respectively. In the pandemic group, there were 191 patients in the prevaccination period and 92 patients in the post-vaccination period. The median age was 51 years (IQR 38-63), and 102 patients were male (50.7\%). General characteristics such as age, sex, ASA score, medical history, and abdominal operation history did not show significant statistical differences among the three groups. No statistical differences were observed in body temperature or pulse rate between the three groups at the time of arrival. Laboratory test results at the time of arrival showed that the DNI value was significantly higher in the pandemic group than in the pre-pandemic group; the other laboratory parameters did not differ among the three groups. In the post-hoc analysis, the DNI value of the P-AV group was significantly higher than that of the $\mathrm{PP}$ and $\mathrm{P}-\mathrm{BV}$ groups ( $\mathrm{P}=0.037$ and $\mathrm{P}=0.032$, respectively);

there were no differences between the PP and P-BV groups. The median TSH during the pandemic was $24 \mathrm{~h}$, significantly longer than the $18 \mathrm{~h}$ of the pre-pandemic group $(\mathrm{P}<0.001)$. However, the THO did not differ between the three groups. The TSO was $24 \mathrm{~h}$ in the pre-pandemic group, $29 \mathrm{~h}$ in the P-BV group, and $31 \mathrm{~h}$ in the P-AV group, showing a significant difference among the three groups (Table 1). In the post-hoc analysis, the median TSH and median TSO did not differ between the P-BV and P-AV groups. Hospital LOS after surgery did not differ between the three groups (Table 2 and Fig. 3). 


\section{Comparison of perioperative characteristics between the three groups}

The type and method of operation did not show a significant difference among the three groups; the operation time was the longest in the pre-pandemic group, with a median value of $50 \mathrm{~min}$. The proportion of complicated appendicitis in pathologic report, including gangrenous change, perforation, or periappendiceal abscess, was significantly higher in the pandemic group than in the pre-pandemic group $(\mathrm{P}=0.003)$. In terms of radiological findings, the proportion of complicated cases, such as those with abscess formation or peritonitis, was significantly higher in the pandemic group than in the prepandemic group $(P=0.004)$. There was no difference between the three groups in the number of cases with sepsis that required treatment in the intensive care unit, and there was no difference in the incidence of postoperative complications between the three groups. The re-hospitalization rate within 30 days after discharge differed between the three groups, with the P-AV group showing the highest value than the other groups (Table 3 and Fig. 4).

\section{Factors associated with the time from symptom onset to hospital arrival}

In linear logistic regression analysis, age, WBC, PLT, and CRP were found to be factors associated with the time from symptom onset to hospital arrival, while multivariate analysis showed that age, daily new cases, vaccination rate, WBC count, PLT, and CRP were independently related factors for the time from symptom onset to hospital arrival. The number of daily new cases showed a positive correlation with the time from symptom onset to hospital arrival $(\mathrm{OR}, 0.03 ; 95 \% \mathrm{Cl}, 0.02$ to $0.04 ; \mathrm{P}<0.001$ ), and the vaccination rate showed a negative correlation with the time from symptom onset to hospital arrival (OR, $-2.26 ; 95 \% \mathrm{Cl},-3.42$ to $-1.11 ; \mathrm{P}<0.001)$.

\section{Factors associated with the time from symptom onset to operation}

Age, daily new cases, vaccination rate, WBC count, PLT count, and CRP level were independently associated with the time from symptom onset to operation in multivariate linear regression analysis. The number of daily new cases showed a positive correlation with the time from symptom onset to operation (OR, $0.03 ; 95 \% \mathrm{Cl}, 0.01$ to $0.04 ; \mathrm{P}<0.001)$, and the vaccination rate showed a negative correlation with the time from symptom onset to operation $(\mathrm{OR},-2.26 ; 95 \% \mathrm{Cl},-3.41$ to $-1.1 ; \mathrm{P}<0.001)$ (Table 4).

\section{Factors associated with complicated appendicitis}

In the binary logistic regression analysis performed to analyze factors associated with complicated appendicitis, age, the number of daily new cases, DNI, and CRP were identified as relevant factors in the univariate analysis. In the multivariate analysis, age, number of daily new cases, vaccination rate, DNI, and CRP were identified as independent relevant factors for complicated appendicitis. The number of daily new cases showed a positive correlation with complicated appendicitis $(\mathrm{OR}, 1.002 ; 95 \% \mathrm{Cl}, 1.001-1.002 ; \mathrm{P}=0.0017)$. The vaccination rate was negatively correlated with complicated appendicitis (odds ratio [OR], $0.915 ; 95 \% \mathrm{Cl}, 0.84$ to $0.996 ; \mathrm{P}=0.0404$ ) (Table 5).

\section{Discussion}

In the COVID-19 era, several variables of patients with acute appendicitis worsened compared to those in the pre-pandemic era. Among them, TSH and TSO first increased during the COVID-19 pandemic period compared to the pre-pandemic 
period in this study. In addition, we found no significant differences in postoperative complications despite a delay in TSH and TSO. Therefore, it is not clear whether the delay itself affects postoperative complications.

Similar to our findings, other studies have also reported a prolonged TSH in the pandemic era [13, 18]. Zheng et al. [13] suggested that the reason for the delay in TSH was that patients were concerned about COVID-19 transmission at the hospital. Another study also explained that the reluctance to visit the ER was due to the government's strong social distancing policy and patients' fear of an in-hospital coronavirus infection [19]. These reasons may lead patients to not see a doctor when they have abdominal pain and other early symptoms of acute appendicitis. The TSO may be prolonged for the same reasons as the TSH because the TSO in the pandemic era was not prolonged compared to that in the pre-pandemic era, as observed in this study.

Our study also showed a rise in cases of complicated appendicitis during the pandemic compared to the pre-pandemic period. This may be associated with delayed TSH. In addition, it also suggests that patients tend to endure symptoms and visit the hospital later in the pandemic era [20]. This may be associated with the new policies formulated during the COVID19 pandemic dealing with social distancing as well as patient fears about contracting the disease from the hospital. Other studies have also reported an increase in the number of complicated appendicitis cases during the pandemic compared to that during the pre-pandemic period [14, 18,21,22]. These studies defined complicated appendicitis using various methods, such as pathological results, radiological findings, or surgical findings. A study by Orthopoulos et al. [14] defined complicated appendicitis based on pathological findings, while a study by Romero et al. [22] classified CT findings into five grades and defined a higher grade as higher severity. In another study, complicated appendicitis was defined according to intraoperative findings [18]. However, discrepancies may exist between CT findings, surgical findings, and pathological results, and complicated appendicitis may not be included in each analysis. Therefore, complicated appendicitis should be classified by considering radiological, intraoperative, and pathological findings simultaneously, as done in the present study. Our criteria may reflect the complicated appendicitis criteria that surgeons use for classification in real-world practice.

Interestingly, as the COVID-19 pandemic situation worsened, that is, as the number of confirmed daily cases increases, the TSH was prolonged and the rate of complicated appendicitis increased. On the other hand, as the cumulative vaccination rate increased, the TSH and the proportion of complicated appendicitis decreased. The number of confirmed cases may negatively influence governmental policies for infection control and the social phobia of being infected with COVID-19. Therefore, hospital arrivals may be delayed, and the number of cases with complicated appendicitis may increase as the number of confirmed COVID-19 cases increases. The Korean government strongly recommended vaccination for individuals, and the vaccine was quickly distributed as a national infection control policy since the first vaccination was started on February 26, 2021. As the cumulative vaccination rate increased, the government's social distancing policy gradually relaxed. In addition, as the proportion of those who were vaccinated increased, the fear of coronavirus infection in the hospital may have gradually decreased. Therefore, patients may feel comfortable visiting the ER without delay after symptom onset. Vaccination may be one of the factors contributing to a shortening of TSH.

While our study reported that the THO was not prolonged during the study period, other studies reported that the THO was prolonged due to the PCR test for COVID-19 screening [20, 23]. In our institution, standard real-time reverse transcriptionpolymerase chain reaction (RT-PCR) was performed for patients who needed to be admitted to general wards or the intensive care unit (ICU) via the ER; however, Xpert Xpress SARS-Cov-2 (Cepheid, USA), which is an automated diagnostic test for the qualitative detection of nucleic acid from SARS-CoV-2, was performed for patients who needed emergency surgery. The standard RT-PCR takes about 6-8 h, while the Xpert test takes about 30 min to 1 hour on average, with an excellent test performance [24]. CT scans are used to diagnose acute appendicitis in Korea after checking creatinine levels. Because it took at least 30 to 60 min to report the serum creatinine level and the result of Xpert was normally reported within that time, the THO may not have increased in our study. The use of rapid PCR tests such as Xpert may help prevent time delay in the treatment of acute appendicitis. 
In the present study, the proportion of patients who received antibiotic therapy with or without percutaneous drainage followed by interval appendectomy increased during the pandemic period, in particular, the $2^{\text {nd }}$ year of the pandemic (2021) compared with that during the pre-pandemic period (PP 2.9\%, P-BV 1.6\%, P-AV 10.7\%, P=0.06, data not shown). The incidence of interval appendectomy may be increased due to the increase in cases of complicated appendicitis resulting from delayed time from symptom onset to ER visit. According to previous studies, interval appendectomy was not inferior to the initial surgical approach in terms of reducing postoperative morbidity [11,25]. Although the initial surgical approach was still preferred in South Korea, interval appendectomy increased as the proportion of complicated appendicitis cases increased during the pandemic. However, conservative management as an initial treatment for acute appendicitis has been recommended in the UK during the COVID-19 pandemic era [12]. The recommendation in the UK and the results of other studies showed that antibiotic application was also effective and non-inferior compared to the initial surgical approach $[10,26]$. A randomized controlled trial with a large number of patients suggested that initial antibiotic therapy was non-inferior to appendectomy based on symptom resolution and the results of a standard health status measure using the European Quality of Life-5 Dimensions (EQ-5D). However, care should be taken in interpretation because an appendectomy was performed in $29 \%$ of the antibiotic group within 90 days, and complications were more common in the antibiotic group in the study [10]. In addition, Sceats et al. [9] demonstrated that the non-operative management of acute appendicitis was associated with higher rates of abscess, readmission, and overall cost of care. Therefore, there is still a debate between the surgical approach and conservative management as initial treatment, and the change in the treatment algorithm for acute appendicitis in the UK could be a great challenge and an inevitable choice in the event of a medical resource shortage during the COVID-19 pandemic. Although it is not possible to determine which is correct because in- and out-of-hospital circumstances are different, some efforts to maintain the mainstream of previous practice, such as the use of a rapid PCR test and rapid distribution of vaccines, are necessary to maintain the quality of treatment for acute appendicitis.

This study has several limitations. First, there was an inevitable selection bias due to its retrospective nature. Second, there may also be a bias due to the heterogeneous decision on treatment and surgical strategy for each surgeon. Third, because this study was conducted based on data from only single institution, it may not reflect the overall trend. Fourth, since the vaccination history of each patient could not be retrospectively confirmed with the medical record, a direct relationship between the actual vaccination history and disease characteristics could not be confirmed.

Despite these limitations, this study is meaningful because we confirmed the trend for 2 years during the pandemic. To our knowledge, this is the first study to include an analysis of the difference in outcomes before and after vaccination and to report the correlation of the number of daily confirmed cases and the cumulative vaccination rate with the outcomes. In addition, this study has an important strength because we classified complicated appendicitis by using radiological, intraoperative, and pathological findings simultaneously to adjust the discrepancies between the results.

\section{Conclusions}

In conclusion, patient hospital arrivals were delayed in the COVID-19 pandemic period compared to those in the prepandemic period. This result may be due to the fear of contracting COVID-19 and the government's stringent social distancing policy. The proportion of complicated appendicitis during the pandemic was higher than that before the pandemic, which may be due to the delayed time to hospital arrival. In addition, with the increase in the number of daily confirmed cases, TSH has been prolonged, and the rate of complicated appendicitis has increased. On the other hand, with the increase in vaccination rate, the TSH decreased, and the rate of complicated appendicitis decreased, possibly due to relaxation of the social distancing policy and reduced fear of visiting the hospital. Following the ER visit, surgery for the patients was not delayed because we used a rapid PCR test for screening. Therefore, in-hospital efforts to avoid further time delay, such as applying rapid PCR tests, and nationwide efforts to shorten the TSH, such as vaccination and creating 
a social atmosphere in which people with symptoms do not hesitate to visit the hospital, are necessary to maintain the quality of treatment for acute appendicitis during an infectious disease pandemic.

\section{List Of Abbreviations}

COVID-19: Coronavirus disease

UK: United kingdom

PP: Pre-pandemic period

P-BV: Before vaccination pandemic period

P-AV: After vaccination pandemic period

LOS: Length of stay

TSH: Time from symptom onset to hospital arrival

THO: Time from hospital arrival to operation

TSO: Time from symptom onset to operation

ASA: American Society of Anesthesiologists physical status

WBC: White blood cell counts

PLT: Platelet count

DNI: Delta neutrophil index

CRP: C-reactive protein

IQR: Interquartile range

OR: Odds ratio

Cl: Confidence interval

RT-PCR: Real-time reverse transcription-polymerase chain reaction

CT: Computed tomography

ER: Emergency room, clinic

\section{Declarations}

\section{Conflict of Interest}

The authors declare that the research was conducted in the absence of any commercial or financial relationships that could be construed as a potential conflict of interest.

\section{Author contributions}


Conceptualization: SHA, KMK; Data collection: SHA; Methodology: SHA, SWJ, KMK; Formal analysis: SWJ, HRK; Investigation: SHA, SWJ, KMK; Writing - Original draft: SHA, SWJ; Writing - Review \& Editing: SHA, SWJ, KMK

\section{Funding}

This study did not receive any specific grant from funding agencies in the public, commercial, or not-for profit sectors.

\section{Acknowledgments}

We thank the staff members of the department of acute care surgery in our hospital for their enthusiasm and commitment to patient care

\section{Data Availability Statement}

The datasets analyzed for this study can be found in the [NAME OF REPOSITORY] [LINK]. Please see the Data Availability section of the Author guidelines for more details.

\section{Ethics declarations}

\section{Consent for publication}

Since the study was performed from the de-identified dataset and a retrospective study. consent from the subject were not applicable.

\section{Ethics approval and consent to participate}

Not applicable.

\section{References}

1. Guan W-j, Ni Z-y, Hu Y, Liang W-h, Ou C-q, He J-x, et al. Clinical characteristics of Coronavirus disease 2019 in China. N Engl J Med. 2020;382:1708-20.

2. Sohrabi C, Alsafi Z, O'Neill N, Khan M, Kerwan A, Al-Jabir A, et al. World Health Organization declares global emergency: A review of the 2019 novel coronavirus (COVID-19). Int J Surg. 2020;76:71-6.

3. Commonwealth of Massachusetts: DPH Public Health Advisory: Stay-at-Home Advisory for Individuals over 70 and for those with underlying health conditions; and Safe Practices for the General Public (2020).

https://www.mass.gov/doc/download-public-health-advisory-3242020/download Accessed 10 Jan 2022.

4. Cucinotta D, Vanelli M. WHO declares COVID-19 a pandemic. Acta Biomed. 2020;91:157-60.

5. Sung HK, Paik JH, Lee YJ, Kang S. Impact of the COVID-19 outbreak on emergency care utilization in patients with acute myocardial infarction: A nationwide population-based study. J Korean Med Sci. 2021;36:e111.

6. Boserup B, McKenney M, Elkbuli A. The impact of the COVID-19 pandemic on emergency department visits and patient safety in the United States. Am J Emerg Med. 2020;38:1732-6.

7. Bhangu A, Soreide K, Di Saverio S, Assarsson JH, Drake FT. Acute appendicitis: Modern understanding of pathogenesis, diagnosis, and management. Lancet. 2015;386:1278-87.

8. Addiss DG, Shaffer N, Fowler BS, Tauxe RV. The epidemiology of appendicitis and appendectomy in the United States. Am J Epidemiol. 1990;132:910-25.

9. Sceats LA, Trickey AW, Morris AM, Kin C, Staudenmayer KL. Nonoperative management of uncomplicated appendicitis among privately insured patients. JAMA Surg. 2019;154:141-9. 
10. The CODA Collaborative. A randomized trial comparing antibiotics with appendectomy for appendicitis. $\mathrm{N}$ Engl J Med. 2021;383:1907-19.

11. Jo YS, Yang SS, Im YC, Park DJ, Kim GY. Therapeutic consideration of reriappendiceal abscess: An evaluation of nonsurgical treatment followed by minimally invasive interval appendectomy. J Minim Invasive Surg. 2017;20:129-36.

12. Javanmard-Emamghissi $H$, Boyd-Carson H, Hollyman M, Doleman B, Adiamah A, Lund JN, et al. The management of adult appendicitis during the COVID-19 pandemic: An interim analysis of a UK cohort study. Tech Coloproctol. 2021;25:401-11.

13. Zheng Z, Bi JT, Liu YQ, Cai X. The impact of COVID-19 pandemic on the treatment of acute appendicitis in China. Int J Colorectal Dis. 2022;37:215-9.

14. Orthopoulos G, Santone E, Izzo F, Tirabassi M, Perez-Caraballo AM, Corriveau N, et al. Increasing incidence of complicated appendicitis during COVID-19 pandemic. Am J Surg. 2021;221:1056-60.

15. Kohler F, Acar L, van den Berg A, Flemming S, Kastner C, Muller S, et al. Impact of the COVID-19 pandemic on appendicitis treatment in Germany-a population-based analysis. Langenbecks Arch Surg. 2021;406:377-83.

16. Kearney D, Cahill RA, O'Brien E, Kirwan WO, Redmond HP. Influence of delays on perforation risk in adults with acute appendicitis. Dis Colon Rectum. 2008;51:1823-7.

17. Korea Disease Control and Prevention Agency: COVID-19 Vaccination (2021). https://ncv.kdca.go.kr/ Accessed 10 Jan 2022.

18. Angeramo CA, Dreifuss NH, Schlottmann F, Rotholtz NA. More severe presentations of acute appendicitis during COVID-19. J Gastrointest Surg. 2021;25:1902-4.

19. Zhang Y, Chen YP, Wang J, Deng Y, Peng D, Zhao L. Anxiety status and influencing factors of rural residents in hunan during the coronavirus disease 2019 epidemic: A web-based cross-sectional survey. Front Psychiatry. 2020;11:564745.

20. Kim CW, Lee SH. Impact of COVID-19 on the care of acute appendicitis: A single-center experience in Korea. Ann Surg Treat Res. 2021;101:240-6.

21. Antakia R, Xanthis A, Georgiades F, Hudson V, Ashcroft J, Rooney S, et al. Acute appendicitis management during the COVID-19 pandemic: A prospective cohort study from a large UK centre. Int J Surg. 2021;86:32-7.

22. Romero J, Valencia S, Guerrero A. Acute appendicitis during coronavirus disease 2019 (COVID-19): Changes in clinical presentation and CT findings. J Am Coll Radiol. 2020;17:1011-3.

23. Lee KY, Lee J, Park YY, Oh ST. Effect of the COVID-19 pandemic on surgical treatment of acute appendicitis: A singlecenter retrospective study. Asian J Surg. 2021;44:800-1.

24. Procop GW, Brock JE, Reineks EZ, Shrestha NK, Demkowicz R, Cook E, et al. A comparison of five SARS-CoV-2 molecular assays with clinical correlations. Am J Clin Pathol. 2021;155:69-78.

25. Mima K, Miyanari N, Itoyama R, Nakao Y, Kato R, Shigaki H, et al. Interval laparoscopic appendectomy after antibiotic therapy for appendiceal abscess in elderly patients. Asian J Endosc Surg. 2020;13:311-8.

26. Collard M, Lakkis Z, Loriau J, Mege D, Sabbagh C, Lefevre JH, et al. Antibiotics alone as an alternative to appendectomy for uncomplicated acute appendicitis in adults: Changes in treatment modalities related to the COVID19 health crisis. J Visc Surg. 2020;157:S33-S42.

\section{Tables}

Table 1. Demographic characteristics of enrolled patients. 


\begin{tabular}{|c|c|c|c|c|}
\hline & Pre-pandemic & Pandemic (BV) & Pandemic (AV) & $P$ value \\
\hline & $(\mathrm{N}=201)$ & $(\mathrm{N}=191)$ & $(\mathrm{N}=92)$ & \\
\hline Age & $51.0[38.0 ; 63.0]$ & $49.0[32.0 ; 63.0]$ & $52.0[36.5 ; 63.5]$ & 0.626 \\
\hline Sex & & & & 0.770 \\
\hline Male & $102(50.7 \%)$ & $103(53.9 \%)$ & $50(54.3 \%)$ & \\
\hline Female & $99(49.3 \%)$ & $88(46.1 \%)$ & $42(45.7 \%)$ & \\
\hline ASA physical status & & & & 0.501 \\
\hline 1 & $58(28.9)$ & $51(26.7)$ & $23(25.0)$ & \\
\hline 2 & $104(51.7)$ & $114(59.7)$ & $50(54.3)$ & \\
\hline 3 & $38(18.9)$ & $26(13.6)$ & $19(20.7)$ & \\
\hline 4 & $1(0.5)$ & $0(0.0)$ & $0(0.0)$ & \\
\hline Medical history & $71(35.3)$ & $82(42.9)$ & $36(39.1)$ & 0.304 \\
\hline Abdominal operation history & $23(11.4)$ & $22(11.5)$ & $7(7.6)$ & 0.559 \\
\hline Body temperature $\left({ }^{\circ} \mathrm{C}\right)$ & $37.0[36.7 ; 37.5]$ & $37.1[36.6 ; 37.7]$ & $37.2[36.8 ; 37.6]$ & 0.686 \\
\hline Pulse rate (beats/minute) & $83.0[71.0 ; 95.0]$ & $86.0[76.0 ; 98.5]$ & $86.0[77.0 ; 98.0]$ & 0.148 \\
\hline White blood cell count $\left(10^{9} / \mathrm{L}\right)$ & $11.0[8.4 ; 14.1]$ & $12.4[9.0 ; 15.1]$ & $12.3[9.8 ; 15.1]$ & 0.142 \\
\hline Hemoglobin $(\mathrm{g} / \mathrm{dL})$ & $14.0[13.0 ; 15.1]$ & $14.2[13.0 ; 15.3]$ & $14.0[13.1 ; 14.8]$ & 0.564 \\
\hline Platelet count $\left(10^{11} / \mathrm{L}\right)$ & $2.3[2.0 ; 2.7]$ & $2.4[2.0 ; 2.9]$ & $2.3[1.9 ; 2.7]$ & 0.564 \\
\hline Neutrophil count $\left(10^{9} / \mathrm{L}\right)$ & $8.7[6.2 ; 12.2]$ & $9.9[6.6 ; 13.0]$ & $9.9[7.5 ; 12.5]$ & 0.113 \\
\hline Lymphocyte count $\left(10^{9} / \mathrm{L}\right)$ & $1.3[0.9 ; 1.9]$ & $1.4[0.9 ; 1.9]$ & $1.3[0.9 ; 1.8]$ & 0.851 \\
\hline Delta neutrophil index (\%) & $0.3[0.0 ; 2.2]$ & $0.4[0.0 ; 2.2]$ & $1.2[0.2 ; 2.5]$ & 0.034 \\
\hline C-reactive protein (mg/dL) & $2.9[0.6 ; 10.2]$ & $3.5[0.4 ; 9.8]$ & $2.6[0.6 ; 8.4]$ & 0.768 \\
\hline Duration of antibiotics use & $4.0[3.0 ; 6.0]$ & $4.0[2.0 ; 7.0]$ & $4.0[2.0 ; 5.5]$ & 0.069 \\
\hline Time from symptom onset to hospital visit (hours) & $18.0[8.0 ; 29.0]$ & $24.0[10.0 ; 48.0]$ & $24.0[12.0 ; 48.0]$ & $<0.001$ \\
\hline Time from hospital visit to operation (hours) & $5.0[4.0 ; 8.0]$ & $5.0[4.0 ; 7.0]$ & $5.0[4.0 ; 6.0]$ & 0.068 \\
\hline Time from symptom onset to operation (hours) & $24.0[15.0 ; 39.0]$ & $29.0[16.0 ; 54.5]$ & $31.0[17.0 ; 52.0]$ & 0.005 \\
\hline LOS after operation (days) & $3.0[2.0 ; 6.0]$ & $4.0[2.0 ; 7.0]$ & $3.0[2.0 ; 5.0]$ & 0.412 \\
\hline
\end{tabular}

Data expressed as median [first quartile; third quartile] for continuous variables and $\mathrm{n}(\%) /$ for nominal variables, BV; Before-vaccination period, AV; After-vaccination period, Hospital LOS; Hospital length of stay,

Table 2. P values of Kruskal-Wallis rank sum test and Dunn's Post-hoc test by Benjamini-Yekuteili adjustment. 


\begin{tabular}{lllll} 
Variable & $\begin{array}{l}\text { Kruskal-Wallis rank sum } \\
\text { test }\end{array}$ & & \multicolumn{2}{l}{$\begin{array}{l}\text { Dunn's Post-hoc test (Benjamini-Yekuteili } \\
\text { adjustment) }\end{array}$} \\
\cline { 2 - 5 } & PP vs PBV & PP vs PAV & PBV vs PAV \\
\hline Delta neutrophil index & 0.034 & 0.757 & 0.037 & 0.032 \\
\hline Time from symptom to arrival & $<0.001$ & 0.001 & 0.007 & 0.886 \\
\hline Time from arrival to operation & 0.068 & 0.563 & 0.062 & 0.086 \\
\hline $\begin{array}{l}\text { Time from symptom to } \\
\text { operation }\end{array}$ & 0.005 & 0.007 & 0.028 & 0.832 \\
\hline
\end{tabular}

In Dunn's post-hoc test by Benjamini-Yekuteili adjustment, the null hypothesis can be rejected when $\mathrm{p}<0.05 / 2, \mathrm{PP}$; Prepandemic, PBV; Before-vaccination period in pandemic, PAV; After-vaccination period in pandemic

Table 3. Therapeutic characteristics of enrolled patients. 


\begin{tabular}{|c|c|c|c|c|}
\hline & Pre-pandemic & Pandemic (BV) & Pandemic (AV) & $P$ value \\
\hline & $(\mathrm{N}=201)$ & $(\mathrm{N}=191)$ & $(\mathrm{N}=92)$ & \\
\hline Operation type (range) & & & & 0.727 \\
\hline Appendectomy & $170(84.6)$ & $157(82.2)$ & $76(82.6)$ & \\
\hline Partial cecectomy & $29(14.4)$ & $28(14.7)$ & $15(16.3)$ & \\
\hline Ileocecectomy & $1(0.5)$ & $3(1.6)$ & $1(1.1)$ & \\
\hline Right hemicolectomy & $1(0.5)$ & $3(1.6)$ & $0(0.0)$ & \\
\hline Operation type (method) & & & & 0.149 \\
\hline Laparoscopy & $191(95.0)$ & $170(89.0)$ & $87(94.6)$ & \\
\hline Open conversion & $5(2.5)$ & $13(6.8)$ & $2(2.2)$ & \\
\hline Laparotomy & $5(2.5)$ & $8(4.2)$ & $3(3.3)$ & \\
\hline Operation time (minutes) & $50.0[35.0 ; 65.0]$ & $40.0[30.0 ; 55.0]$ & $45.0[25.0 ; 65.0]$ & 0.015 \\
\hline Pathological type & & & & 0.031 \\
\hline Normal appendix & $4(2.0)$ & $2(1.0)$ & $3(3.3)$ & \\
\hline Simple appendicitis & $48(23.9)$ & $24(12.6)$ & $15(16.3)$ & \\
\hline Suppurative appendicitis & $95(47.3)$ & $84(44.0)$ & $37(40.2)$ & \\
\hline Gangrenous appendicitis & $4(2.0)$ & $4(2.1)$ & $4(4.3)$ & \\
\hline Perforated appendicitis & $38(18.9)$ & $51(26.7)$ & $22(23.9)$ & \\
\hline Periappendiceal abscess & $12(6.0)$ & $26(13.6)$ & $11(12.0)$ & \\
\hline Radiological findings & & & & $<0.001$ \\
\hline Normal appendix & $7(3.5)$ & $3(1.6)$ & $2(2.2)$ & \\
\hline Simple appendicitis & $153(76.1)$ & $129(67.5)$ & $55(59.8)$ & \\
\hline Abscess, localized peritonitis & $37(18.4)$ & $51(26.7)$ & $14(15.2)$ & \\
\hline Generalized peritonitis & $4(2.0)$ & $8(4.2)$ & $21(22.8)$ & \\
\hline Complicated appendicitis & $65(32.3)$ & $93(48.7)$ & $51(55.4)$ & 0.003 \\
\hline \multicolumn{5}{|c|}{ Criteria for complicated appendicitis } \\
\hline Operation type & $31(15.4)$ & $34(17.8)$ & $16(17.4)$ & 0.806 \\
\hline Pathological type & $54(26.9)$ & $81(42.4)$ & $37(40.2)$ & 0.003 \\
\hline Radiological type & $41(20.4)$ & $59(30.9)$ & $35(38.0)$ & 0.004 \\
\hline Numbers that meet the criteria & & & & $<0.001$ \\
\hline 1 & $22(10.9)$ & $37(19.4)$ & $23(25.0)$ & \\
\hline 2 & $25(12.4)$ & $31(16.2)$ & $19(20.7)$ & \\
\hline 3 & $18(9.0)$ & $25(13.1)$ & $9(9.8)$ & \\
\hline Admission to ICU & $9(4.5)$ & $12(6.3)$ & $4(4.3)$ & 0.668 \\
\hline
\end{tabular}

Page 13/19 
Complication

\begin{tabular}{lllll}
\hline Surgical site infection & $19(9.5)$ & $26(13.6)$ & $13(14.1)$ & \\
\hline Intra-abdominal abscess & $4(2.0)$ & $5(2.6)$ & $2(2.2)$ & \\
\hline Postoperative ileus & $11(5.5)$ & $17(8.9)$ & $3(3.3)$ & \\
\hline Pulmonary complication & $2(1.0)$ & $4(2.1)$ & $0(0.0)$ & \\
\hline Enteritis & $1(0.5)$ & $3(1.6)$ & $0(0.0)$ & \\
\hline Myocardial infarction & $0(0.0)$ & $0(0.0)$ & $1(1.1)$ & \\
\hline Re-admission after discharge & $5(2.5)$ & $4(2.1)$ & $7(7.7)$ & 0.035
\end{tabular}

Data expressed as n (\%) for nominal variables, BV; Before-vaccination period, AV; After-vaccination period, ICU; Intensive care unit.

Table 4. Linear regression for time from symptom onset to hospitalization and time from symptom onset to operation.

Time from symptom onset to hospitalization

Univariate

OR $(95 \% \quad P$

Cl) value

Age

$\begin{array}{ll}0.39(0.21, & < \\ 0.57) & 0.001\end{array}$

$0.42)$
Multivariate

OR $(95 \% \quad P$

Cl) value
Time from symptom onset to operation

Univariate Multivariate

OR $(95 \% \quad P \quad$ OR $(95 \% \quad P$

Cl) value $\mathrm{Cl}$ value

$0.25(0.07, \quad 0.006$

$\begin{array}{llll}0.39(0.21, & < & 0.25(0.08, & 0.005 \\ 0.56) & 0.001 & 0.43)\end{array}$

Sex

\begin{tabular}{|c|c|c|c|c|c|c|c|c|}
\hline Male & (Reference) & & (Reference) & & (Reference) & & (Reference) & \\
\hline Female & $\begin{array}{l}-1.19 \\
(-8.07 \\
5.68)\end{array}$ & 0.734 & $\begin{array}{l}-4.26 \\
(-10.59 \\
2.07)\end{array}$ & 0.188 & $\begin{array}{l}-1.21 \\
(-8.08 \\
5.65)\end{array}$ & 0.729 & $\begin{array}{l}-4.29 \\
(-10.64 \\
2.06)\end{array}$ & 0.186 \\
\hline $\begin{array}{l}\text { Daily new } \\
\text { cases }\end{array}$ & $\begin{array}{l}0.00(0.00 \\
0.01)\end{array}$ & 0.254 & $\begin{array}{l}0.03(0.02 \\
0.04)\end{array}$ & $\begin{array}{l}< \\
0.001\end{array}$ & $\begin{array}{l}0.00(0.00 \\
0.01)\end{array}$ & 0.316 & $\begin{array}{l}0.03(0.01 \\
0.04)\end{array}$ & $<.001$ \\
\hline $\begin{array}{l}\text { Vaccinated } \\
\text { rate }\end{array}$ & $\begin{array}{l}-0.20 \\
(-0.89 \\
0.50)\end{array}$ & 0.578 & $\begin{array}{l}-2.26 \\
(-3.42 \\
-1.11)\end{array}$ & $\begin{array}{l}< \\
0.001\end{array}$ & $\begin{array}{l}-0.24 \\
(-0.93 \\
0.45)\end{array}$ & 0.496 & $\begin{array}{l}-2.26 \\
(-3.41,-1.1)\end{array}$ & $<.001$ \\
\hline WBC count & $\begin{array}{l}-0.94 \\
(-1.78 \\
-0.10)\end{array}$ & 0.028 & $\begin{array}{l}-1.53 \\
(-2.32 \\
-0.74)\end{array}$ & $\begin{array}{l}< \\
0.001\end{array}$ & $\begin{array}{l}-0.89 \\
(-1.73 \\
-0.05)\end{array}$ & 0.038 & $\begin{array}{l}-1.47 \\
(-2.26 \\
-0.67)\end{array}$ & $<.001$ \\
\hline $\begin{array}{l}\text { Platelet } \\
\text { count }\end{array}$ & $\begin{array}{l}0.07(0.02, \\
0.12)\end{array}$ & 0.004 & $\begin{array}{l}0.13(0.08, \\
0.17)\end{array}$ & $<0.001$ & $\begin{array}{l}0.07(0.02, \\
0.12)\end{array}$ & 0.004 & $\begin{array}{l}0.13(0.08 \\
0.17)\end{array}$ & $<.001$ \\
\hline CRP & $\begin{array}{l}1.49(1.09, \\
1.88)\end{array}$ & $\begin{array}{l}< \\
0.001\end{array}$ & $\begin{array}{l}1.51(1.11, \\
1.90)\end{array}$ & $\begin{array}{l}< \\
0.001\end{array}$ & $\begin{array}{l}1.44(1.05, \\
1.84)\end{array}$ & $\begin{array}{l}< \\
0.001\end{array}$ & $\begin{array}{l}1.45(1.05 \\
1.85)\end{array}$ & $\begin{array}{l}< \\
0.001\end{array}$ \\
\hline
\end{tabular}

OR; Odd ratio, Cl; Confidence interval, WBC; White blood cells, CRP; C-reactive protein

Table 5. Univariate \& Multivariate binary logistic regression for complicated appendicitis and Ordinal regression for numbers that meet the criteria for complicated appendicitis. 


\begin{tabular}{|c|c|c|c|c|}
\hline & \multicolumn{2}{|l|}{ Univariate } & \multicolumn{2}{|l|}{ Multivariate } \\
\hline & \multicolumn{4}{|c|}{ Binary logistic regression } \\
\hline & OR (95\% Cl) & $P$ value & OR $(95 \% \mathrm{Cl})$ & $P$ value \\
\hline Age & $1.035(1.024,1.046)$ & $<0.001$ & $1.024(1.011,1.037)$ & $<0.001$ \\
\hline \multicolumn{5}{|l|}{ Sex } \\
\hline Male & \multicolumn{2}{|l|}{ (Reference) } & \multicolumn{2}{|l|}{ (Reference) } \\
\hline Female & $0.868(0.604,1.246)$ & 0.443 & $0.857(0.545,1.347)$ & 0.504 \\
\hline Daily new cases & $1.001(1.000,1.001)$ & 0.022 & $1.002(1.001,1.002)$ & 0.0017 \\
\hline Vaccinated rate & $1.024(0.987,1.062)$ & 0.2018 & $0.915(0.84,0.996)$ & 0.0404 \\
\hline WBC count & $1.017(0.973,1.063)$ & 0.4594 & $1.01(0.952,1.072)$ & 0.7318 \\
\hline Platelet count & $0.999(0.996,1.001)$ & 0.3162 & $1.003(0.999,1.006)$ & 0.1304 \\
\hline DNI & $1.293(1.182,1.416)$ & $<0.001$ & $1.115(1.012,1.228)$ & 0.0272 \\
\hline CRP & $1.188(1.144,1.234)$ & $<0.001$ & $1.159(1.114,1.206)$ & $<0.001$ \\
\hline \multicolumn{5}{|c|}{ Hosmer \& Lemeshow goodness of fit test $\quad P=0.509$} \\
\hline \multicolumn{2}{|c|}{ AUC of ROC curve $(95 \% \mathrm{Cl})$} & $91-0.866)$ & & \\
\hline
\end{tabular}

OR; Odd ratio, Cl; Confidence interval, WBC; White blood cells, DNl; Delta neutrophil index, CRP; C-reactive protein, AUC; Area under curve, ROC; Receiver operating characteristic

\section{Figures}




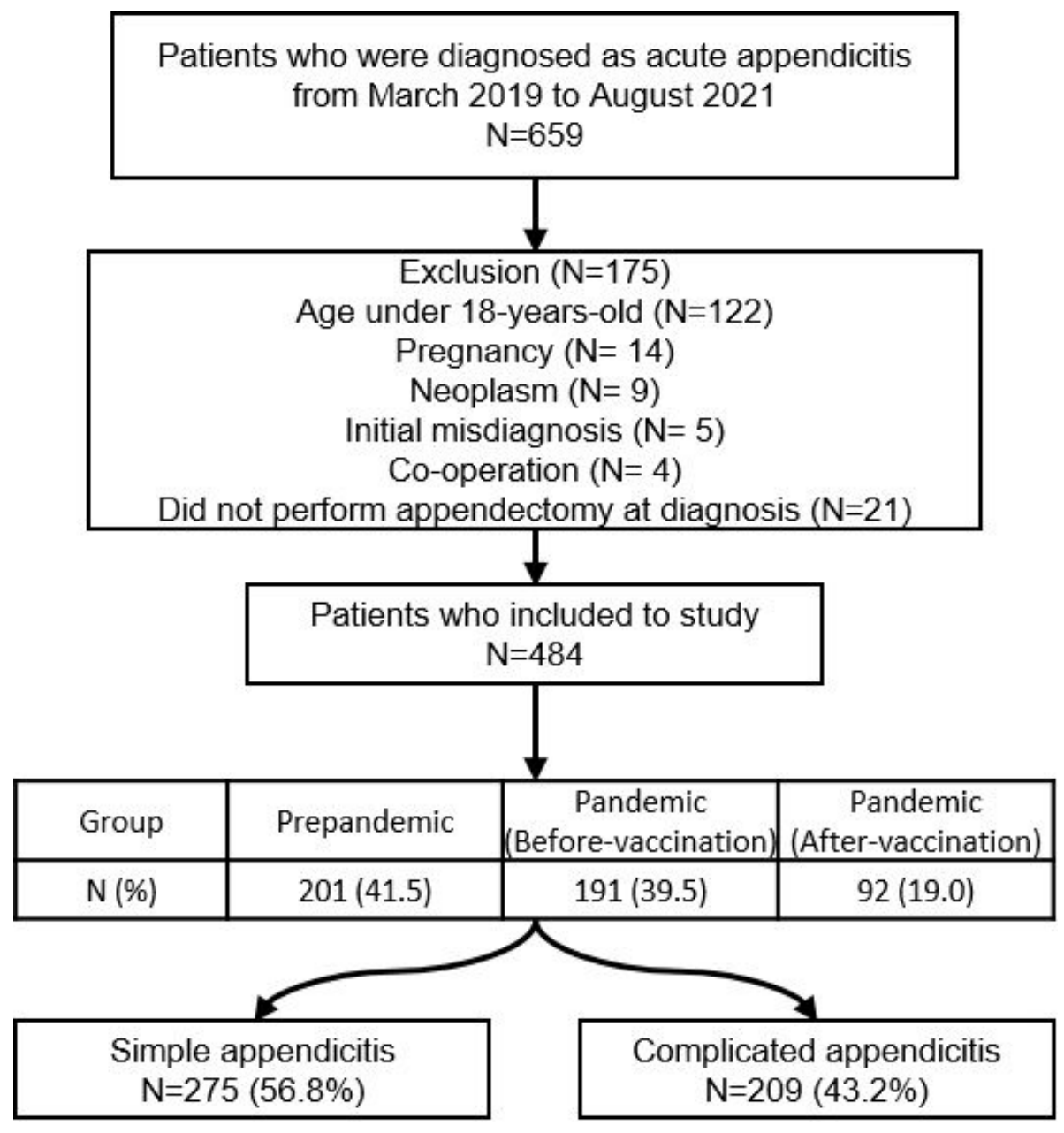

Figure 1

Patients included in the study 


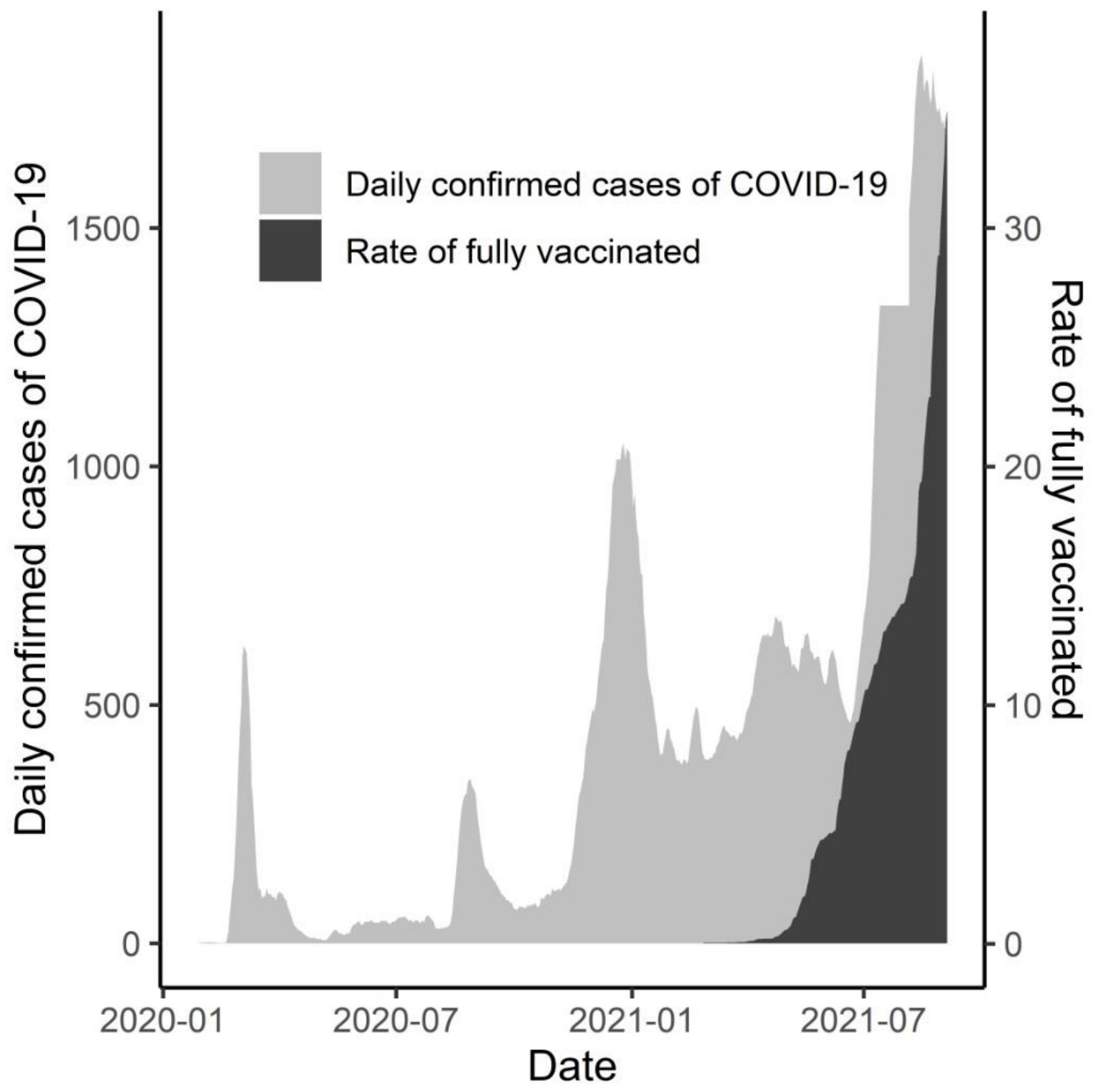

Figure 2

Daily confirmed cases of COVID-19 and percentage of fully vaccinated individuals until August 31, 2021 
(A)

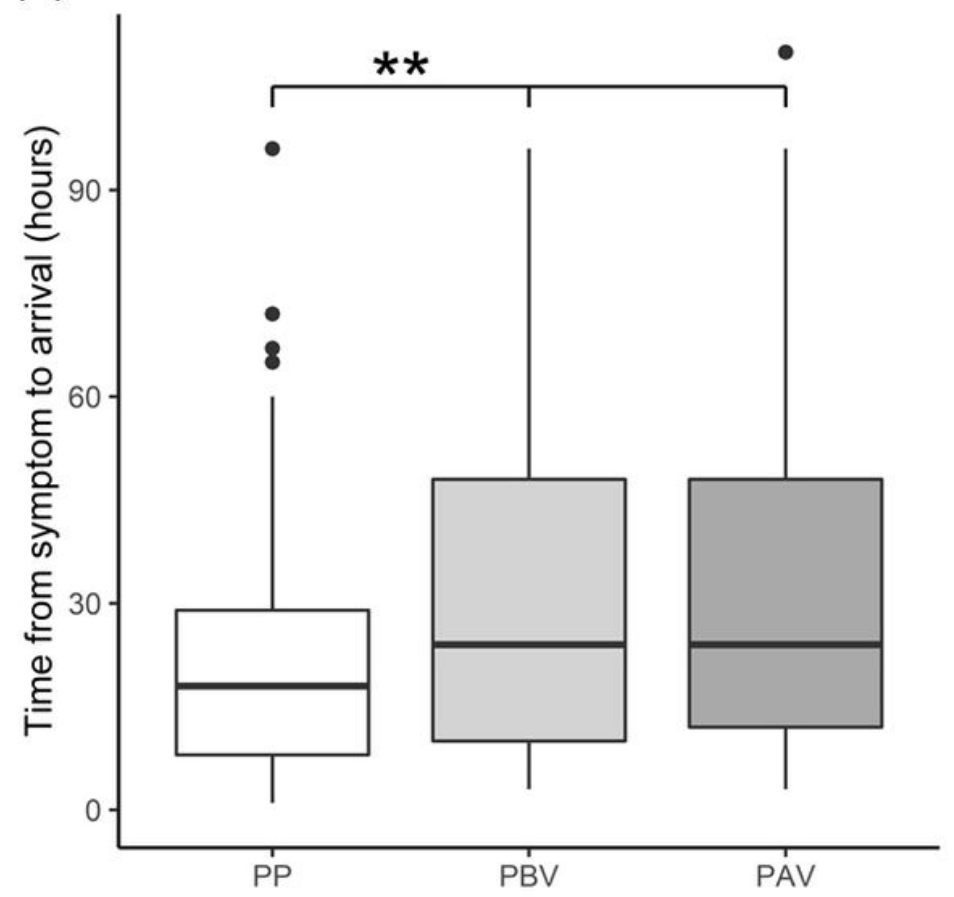

(B)

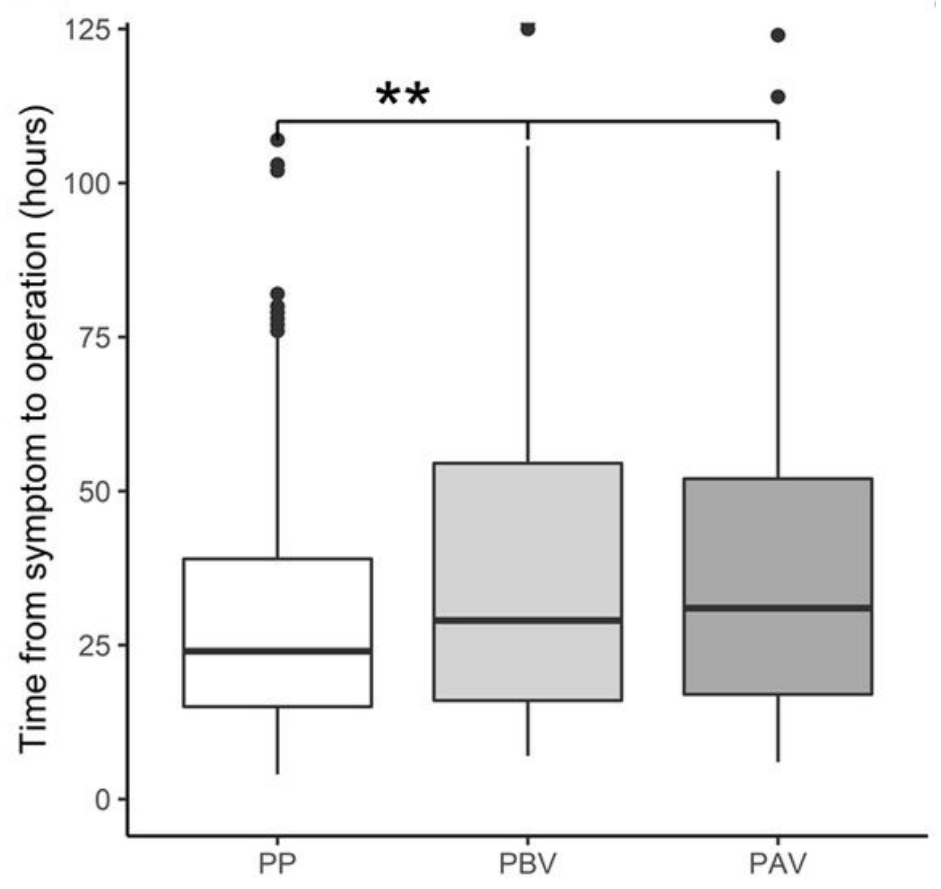

Figure 3

Hospital length of stay between the three groups 


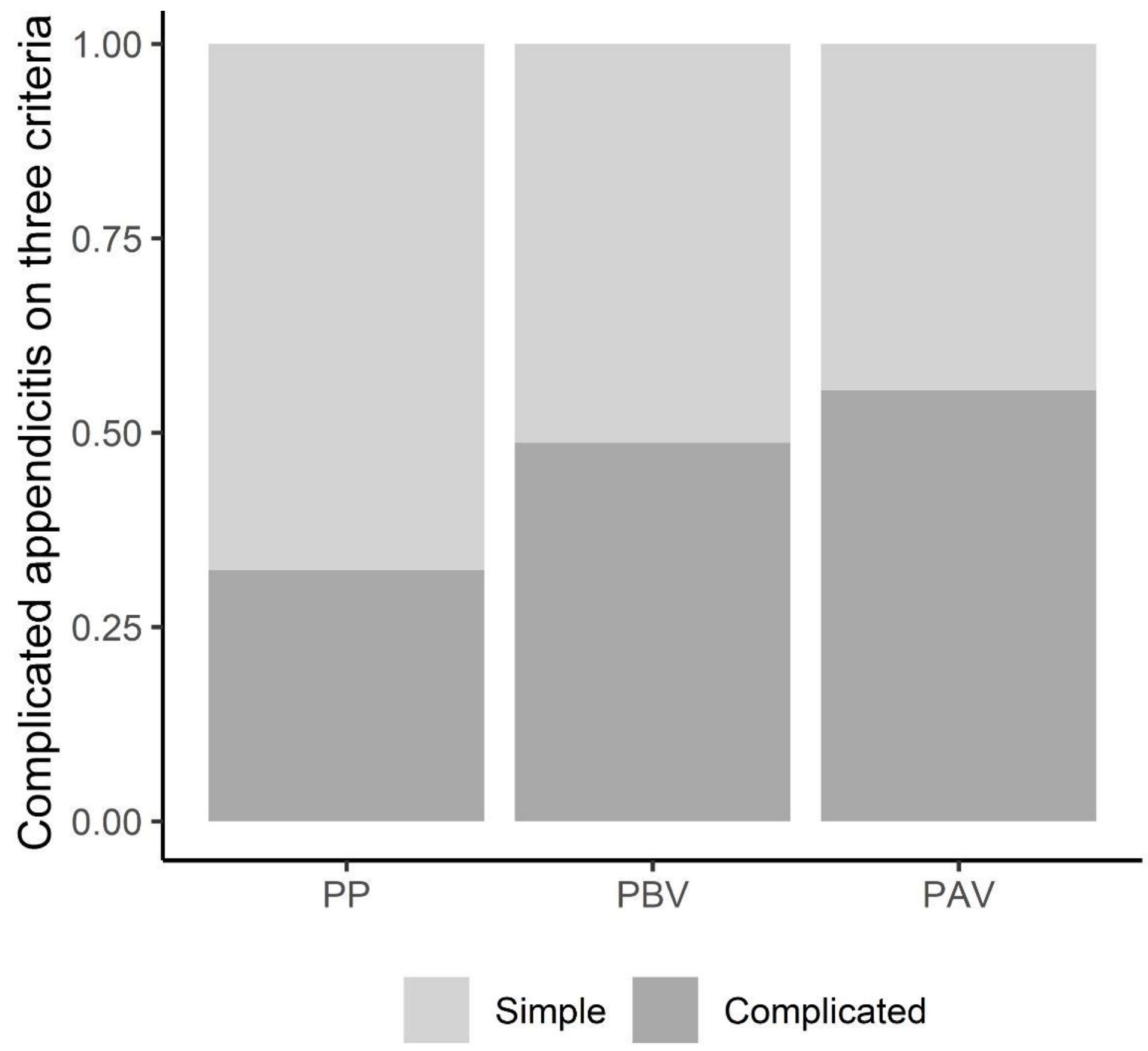

Figure 4

Re-hospitalization rate within 30 days after discharge between the three groups 